\title{
"Haquapathy" - The Most Natural Holistic Approach to Weight Loss
}

\section{Faris Al Hajri*}

Haqua Revitalize ${ }^{\circledR}$ Therapy, President and CEO of Haqua Wellness, Virginia, USA

*Corresponding Author: Faris Al Hajri, Haqua Revitalize Therapy ${ }^{\circledR}$, President and CEO of Haqua Wellness, Virginia, USA.

DOI: 10.31080/ASNE.2020.03.0213
Received: July 01, 2020

Published: July 30, 2020

(C) All rights are reserved by Faris Al Hajri.
What is the concept of "Haquapathy"?

The name "Haquapathy" is the implementation of the entire Haqua Revitalize ${ }^{\circ}$ Therapy, covering all the internal and external therapeutic modalities.

"Haqua" derives from two words "hot", and "aqua" from the Latin word "water". Thus hot aqua simply means hot water.

Revitalize represents the reinstatement of the human's body to its initial state of creation in the precise form of complete PEMS (Physical, Emotional, Mental and Spiritual) health.

Haquate means to make the body absorb the elements found in hot water, coined as the Four Essential Elements of Life (FEEL).

Haquapathy is one of the basic methods of revitalization in the system of natural medicine, which we also coined it as Haqua Revitalize ${ }^{\circledR}$ Therapy (HART), otherwise known as; Hot Aqua Therapy (HAT), Hot Water Therapy (HOWT), Hydrothermal Therapy (HTT), Aqua Calidum Therapy (ACT), Maysakhin Therapy (MST), and Majimoto Therapy (MMT), that we instigated, being the originator and founder of this therapy since we discovered its significant health benefits to the human body in August 2007, until the present moment.

Haquapathic Medicine is a newly introduced form of primary health care profession, emphasizing prevention, revitalization, and optimal health through the use of Haqua Revitalize ${ }^{\circ}$ Therapy toward individuals' inherent self-healing, self-protection and selfmaintenance process.

\section{Weight loss}

Weight loss is achieved by burning more calories than the daily number of calories consumed. By increasing the metabolism, this process is more easily achieved.

Some who have a low metabolism struggle to lose weight, no matter what diet they try. Others have a high metabolism and they easily burn more calories and maintain their weight, even without dieting or exercise. However, in both cases, there can be a buildup of cholesterol in the blood. Both those who are overweight and those with a 'healthy' weight can develop diabetes. So, what is the answer?

In adopting the Haqua Diet Therapy (HDT), we have observed that a calorie is interrelated with hot water, or 'Haqua'. Simply, the amount of water in relation to heat is consistent with our scientific idea of the calorie.

Fat deposits in our bodies, known as lipids, are solidified by cold water. Through the use of hot water, Haqua Revitalize ${ }^{\circledR}$ Therapy (HART) enhances the decomposition of fats into fatty acids through 'haquation', speeding up the metabolic reactions, and using them as sources of energy. Excessive fats are then excreted as waste.

One of the hidden mysteries of HART and its direct link to calorie-burning is that heat and calories are almost the same substance. The energy provided by food is measured in kilocalories, or Calories. One kilocalorie is equal to 1,000 gram-calories (small calories), which is also a measure of heat energy.

A calorie is scientifically defined as the amount of heat required to raise the temperature of one gram of water from 14.5 degrees Celsius to 15.5 degrees Celsius [1].

One kilocalorie is the amount of heat energy required to raise one kilogram of water from 14.5 to $15.5^{\circ} \mathrm{C}$ at one atmosphere of pressure [2].

Simply put, two elements are involved in measuring the effects calories have in our bodies: water and heat.

\section{Water temperature}

Why does the water need to be raised to a precise $14.5^{\circ} \mathrm{C}$ ? The answer is simple. Water is cold at any temperature below $14.5^{\circ} \mathrm{C}$.

There is much dispute about who discovered the 'Calorie'. It is believed that the Calorie was first defined by Nicolas Clément 


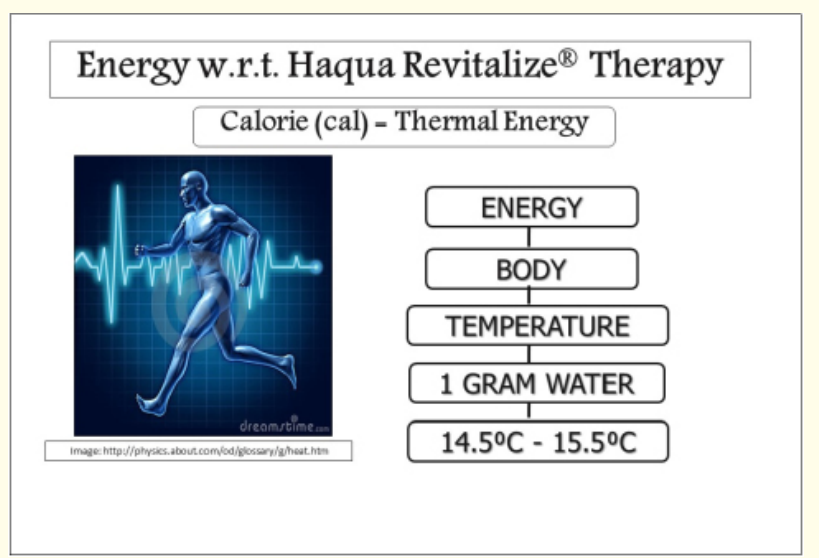

Figure 1

in 1824 as a unit of heat [3]. Two Frenchmen-P.A. Favre and J.T. Silbermann-popularized the Calorie in 1852. Other texts also state that a German physician, Julius Mayer, effectively invented the Calorie in a study that he published in 1848 [4].

Whoever is responsible, calories have been scientifically understood as units of heat for quite some time. We hypothesized that the calorie was discovered by using heat and water at a room temperature of the water at $14.5^{\circ} \mathrm{C}$. With one gram of water (for the small calorie) or kilogram of water (for the big Calorie), placed at each degree Celsius, one Calorie or one kilocalorie was created.

This scientific hypothesis directly links Haqua (hot water) to the calorie. Food and exercise are simply a secondary method of explaining or regulating calories. Gulping a glass of $500 \mathrm{ml}(17 \mathrm{Oz})$ Haqua (hot water) at $50^{\circ} \mathrm{C}\left(122^{\circ} \mathrm{F}\right)$ would naturally have a superior effect on burning calories in comparison to exercise or altering the daily food intake.

The Therapeutic Methods of Haqua Gulping (TMHG) effortlessly accomplishes the goal of burning calories exclusively by 'haquation.' The energy freely and effortlessly flows from the hot water to the body in a principle reinforced by the Laws of Thermodynamics. Following the implementations of Haqua Revitalize ${ }^{\circledR}$ Therapy (HART), along with a minimum of daily exercise, a reduced food intake, and moderate sunbathing, is more than enough for human health and wellness.

The First Law of Thermodynamics states that the change in a system's internal energy is equal to the difference between heat added to the system from its surroundings and work done by the system on its surroundings.

When heat is added to a system, there are two possible changes: the internal energy will alter, or the system will begin working. (Or both will occur at the same time) [5].

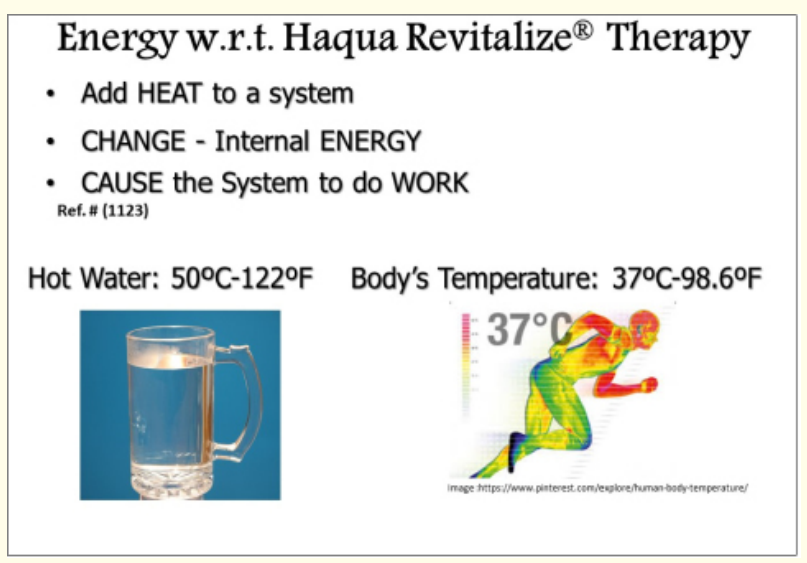

Figure 2

The human body's normal temperature ranges between 36.5 $37^{\circ} \mathrm{C}\left(97.7-98.6^{\circ} \mathrm{F}\right)$. For our hypothesis, Haqua Revitalize ${ }^{\circledR}$ Therapy (HART) will cause the body's internal energy change to $13-13.5^{\circ} \mathrm{C}$ $\left(55.4-56.3^{\circ} \mathrm{F}\right)$ for adults, and $3-3.5^{\circ} \mathrm{C}\left(37.4-38.3^{\circ} \mathrm{F}\right)$ for infants and small children.

This is very interesting discovery, as we know that this therapy is directly linked to energy and irreversibly institutes the essential component of the human's biology.

Taking into consideration that the human body mass is threequarters water, any person performing exercise-the kinetic movement of the muscles-would experience heat energy by thermogenesis. This dilates the blood veins and, finally, burns calories. In many cases, therefore, Haqua Revitalize ${ }^{\circledR}$ Therapy (HART) can be substituted for intensive exercise, as it accomplishes the same calorie-burning.) to (therefore intensive exercise can be substituted by Haqua Revitalize ${ }^{\circledR}$ Therapy (HART), as it accomplishes the same calorie-burning, except in the event of sporting activities and sports competitions.

Moderate exercise is still encouraged, with the strong recommendation of gulping a tumbler of $500 \mathrm{ml}$ (17 oz) of Haqua (hot water) at every half-hour of exercise.

The energy used to strengthen the muscles, and other body metabolisms, will be fully compensated through the Haqua Revitalize ${ }^{\circledR}$ Therapy.

Cold or warm water requires more effort from the body to achieve the energy needed, and thus is not as affective for physical needs. Various side-effects may also occur from drinking cold water.

\section{Obesity}

Obesity, also called corpulence or fatness, is an excessive accumulation of body fat, usually caused by the consumption of 
more calories than the body can use. The excess calories are then stored as fat, or adipose tissue. Muscular or large-boned individuals, however, may have a moderate level of more fat without necessarily being obese.

Compared to normal-weight individuals, obese persons are more likely to die prematurely of degenerative diseases of the heart, arteries, and kidneys. They also have an increased risk of developing cancer and serious accidents. Obese individuals often create surgical risks; mental health is affected; and behavioral consequences may appear [6].

Diet is the cornerstone of diabetic treatment even if insulin is prescribed. The goal is to regulate the patient's blood glucose level to as close to normal as possible. Obesity contributes to hypertension and increases the risk of cardiovascular disease [7].

Individuals who follow the Haqua Revitalize ${ }^{\circledR}$ Therapy (HART) will naturally burn their extra calories, especially if they consider the two main modalities for weight loss and eradication of obesity: Therapeutic Methods of Haqua Gulping (TMHG) and Haqua Compress Therapy (HCT).

Thermogenesis, known as the generation or production of heat, especially by physiological processes [8], can also potentially be stimulated to increase energy expenditure and fat oxidation [9].

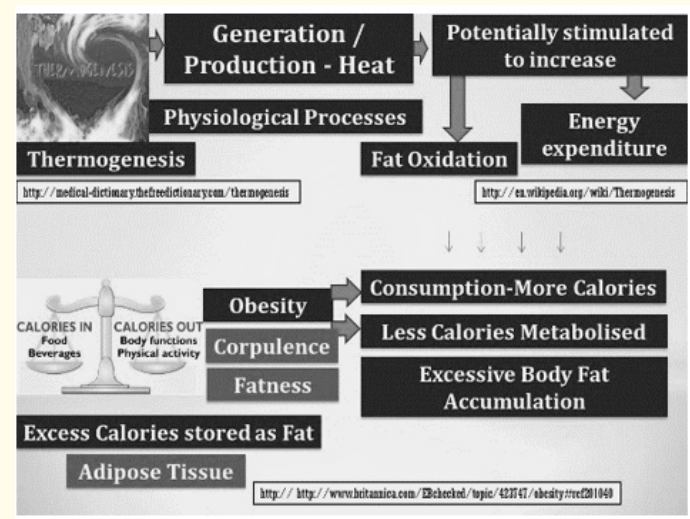

Figure 3

Researchers at Loughborough University in the UK found that men who took an hour-long hot bath burned as many calories as if they had taken a 30-minute brisk walk - about 140 calories [10].

The Haqua Compress Therapy is correlated to vast scientific research that we have conducted on the benefits of sunlight, which emits vast amounts of energy through the ultraviolet (UV) rays which generate heat.
But the most serious concern to this benefit lies in various scientific research on the detrimental health effects of overexposure to the sun, which can cause skin cancer.

In 1904, it was discovered that sunlight changes the cholesterol just under the skin into vitamin D. Because there is so much cholesterol under the skin, this change causes more cholesterol in the bloodstream to flow under the skin, thus lowering the cholesterol in the blood. And when cholesterol is removed from the blood, the cholesterol stored in plaques deposited on artery walls takes its place and is then subsequently lowered as well. Sunlight increases thyroid production and leads to further weight loss. But, how are humans to acquire the benefits of sunlight without the toxic effects of overexposure?

The answer is Haqua Revitalize ${ }^{\circledR}$ Therapy (HART) which both hydrates the skin cells and enhances the body's energy to the same effect as sunlight. All energy received from thermogenesis during this therapy will further enhance the eradication of excessive fat deposits in the blood.

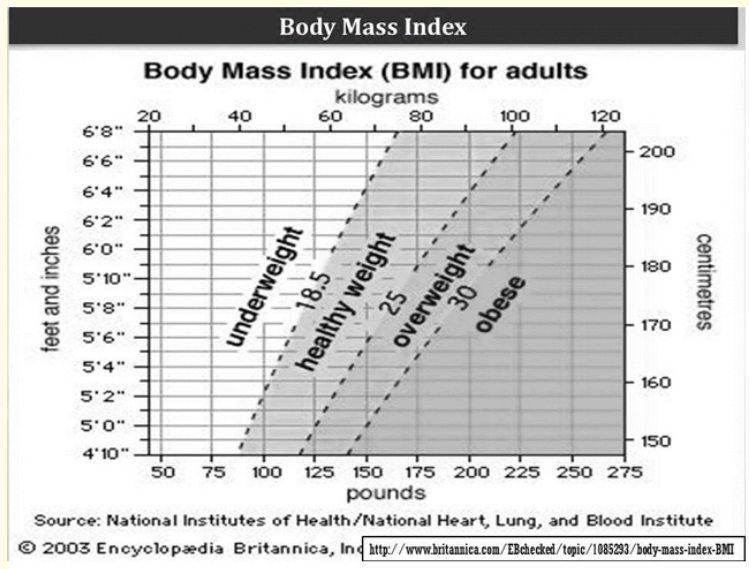

Figure 4

\section{Measuring obesity}

The body mass index (BMI) is an estimate of total body fat. The BMI is defined as weight in kilograms divided by the square of the height in meters: weight/height ${ }^{2}=$ BMI. This number, which is central to determining whether an individual is clinically defined as obese, parallels fatness but is not a direct measure of body fat [11].

\section{Stress}

Stress is another concern that we have been expanding our research to include in relation to weight gain. One of the major threats that lead to obesity, stress causes an emotional imbalance that is 
sent to the human brain. This triggers the brain and often results in hormonal imbalances in the body. Haqua Revitalize ${ }^{\circledR}$ Therapy (HART) aids in regulating a proper hormonal balance regarding stress in the body.

Stress is everywhere in our life. It targets all ages, including children. During a stress response, one of the most common hormones released is cortisol, a steroid hormone produced by the adrenal gland-the gland that sits at the top of the kidneys. Its primary function is to redistribute energy (glucose) to regions of the body that need it most (i.e. the brain and major muscles during a fightor-flight situation). As a part of the body's fight-or-flight response, cortisol also acts as a suppressant to the body's immune system.

Cortisol is produced from cholesterol in the adrenal cortex-the gland situated along the perimeter of the adrenal gland. Its primary function is to increase blood sugar through gluconeogenesis-the metabolic process by which organisms produce sugars (namely glucose) for catabolic reactions from a non-carbohydrate-suppress the immune system, and aid in fat and protein metabolism.

Cortisol is the main glucocorticoid-a hormone that largely affects the metabolism of carbohydrates, fats and proteins-under normal conditions and its actions include mobilization of fats, proteins, and carbohydrates, but it does not increase under starvation conditions [12].

Stress affects the redistribution of glucose (blood sugar), which affects the body's energy; the same applies in vice versa.

Haqua Revitalize ${ }^{\circledR}$ Therapy (HART) changes all these principles. It aids in proper hormone emission, regulates the blood sugar and fatty acids for the body's energy, redistributes all vitamins efficiently, eradicates obesity, and leads to weight loss.

\section{Economic impact of obesity and statistics}

It is estimated that losses in gross domestic product, including both direct and indirect costs of diabetes, will total US $\$ 1.7$ trillion, comprising in US $\$ 800$ billion for low- and middle-income countries. Besides the economic burden on the health-care system and national economy, diabetes often imposes catastrophic personal expenditures from out-of-pocket payments and loss of income due to disability and premature death. One and a half million people died directly from diabetes in 2012. However, blood glucose levels that are higher than optimal but are below the diagnostic threshold for diabetes also increases the risk of death, particularly from CVD, and have caused an additional 2.2 million deaths. The number of people with diabetes has increased from 180 million in 1980 to 422 million in 2014. Research in several parts of the world and different populations has consistently shown that people with im- paired glucose tolerance (IGT) and who are overweight or obese can substantially lower their risk of Type 2 diabetes by a healthy diet and physical activity. Several medicines have also been shown to lower this risk, but less effectively than diet and physical activity [13].

According to a report issued by the World health organization in 2017, worldwide obesity has nearly tripled since 1975.

In 2016, more than 1.9 billion adults aged 18 years and older were overweight. Of these over 650 million adults were obese. In $2016,39 \%$ of adults aged 18 years and over (39\% of men and $40 \%$ of women) were overweight. Overall, about $13 \%$ of the world's adult population ( $11 \%$ of men and $15 \%$ of women) were obese in 2016. The worldwide prevalence of obesity nearly tripled between 1975 and 2016.

Common health consequences of overweight and obesity:

- Cardiovascular diseases (mainly heart disease and stroke), which were the leading cause of death in 2012

- Diabetes

- Musculoskeletal disorders (especially osteoarthritis - a highly disabling degenerative disease of the joints)

- Some cancers (including endometrial, breast, ovarian, prostate, liver, gallbladder, kidney, and colon) [14].

Treating obesity and obesity-related conditions costs billions of dollars a year. In one of the earliest analyses, Dr. Graham Colditz, Washington University, looked at the direct and indirect costs in the U.S. of six common obesity-related conditions-type 2 diabetes, high blood pressure, cardiovascular disease, gallbladder disease, colon cancer, and postmenopausal breast cancer-and determined what percentage of those costs were due to obesity. He estimated that in 1986 , obesity was responsible for 5.5 percent of the direct and indirect costs associated with these common medical conditions, or about $\$ 39$ billion [15]

Some reminders on Haqua Revitalize ${ }^{\circledR}$ therapy (HART) and weight loss

- $\quad$ Avoid putting any additives in your Haqua (hot water). Doing so changes the chemical form of water. Herbal teas or flavored water will not harm your health, but these should not be substituted for your daily intake of plain hot water.

- $\quad$ To lose and maintain a proper weight, you need to fully abide with the Therapeutic Methods of Haqua Gulping (TMHG) as recommended. Continue with moderate exercise and gradually lower your food intake by $50-70 \%$. 
- Metabolic waste is comprised of toxic substances that lead to various health effects. The human body does not excrete all metabolic waste. Haqua Revitalize ${ }^{\circledR}$ Therapy (HART) safeguards the provision of the Body's Essential Fuels (BEF), otherwise coined the FEEL -water, oxygen, hydrogen, and energyand aids in complete excretion of all metabolic wastes from the body.

- $\quad$ Enjoy your Haqua Revitalize ${ }^{\circledR}$ Therapy (HART) for the different aspects of your physical, emotional, mental, and spiritual health.

- Once or twice a week, there is an opportunity to eat large meals. These days are for you to enjoy food and not to feel guilty about eating more than normal. However, they should only occur a few times a week instead of every day.

Does Haqua pose any concern to underweight people?

Though Haqua Revitalize ${ }^{\circledR}$ Therapy (HART) is a therapy that more dominantly aids in weight loss, there should not be any concern for those who are underweight due to any of the following reasons:

- Genetics [16-18] metabolism, drug use, lack of food (frequently due to poverty), or illness (both physical and mental).

- $\quad$ Eating disorders. People with certain eating disorders can be underweight due to a lack of nutrients or over exercising.

- Certain medical conditions.

- Gastrointestinal or liver problems that may cause an inability to absorb nutrients adequately.

- Being underweight is an established $[16,19]$ risk factor for osteoporosis-a progressive bone disease that is characterized by a decrease in bone mass and density-even for young people. Weight loss is also associated with bone loss, although an adequate diet and physical activity may reduce this loss [20].

Because this therapy is natural and works with the body's unique needs, there can be many health benefits for those who are underweight as well as those with a myriad of other health struggles.

\section{Bibliography}

1. Heat Energy - Definition and Examples. about education.

2. Human nutrition. Encyclopaedia Britannica.

3. Who discovered calories? What system did they use to measure how many calories are in foods? And how do they affect our bodies? Quora.
4. Laws of Thermodynamics. Andrew Zimmerman Jones.

5. University of Georgia. "Confusion About Calories Is Nothing New, Professor Finds". ScienceDaily (2006).

6. Obesity. Encyclopaedia Britannica.

7. Therapeutics. Encyclopaedia Britannica.

8. Thermogenesis. The free dictionary.

9. Thermogenesis. Wikipedia. The free encyclopedia.

10. Michael Smith MD. CPT. Is a Hot Bath Really as Good as Exercise? WEBMD DOCTORS (2018).

11. Body mass index. Encyclopaedia Britannica.

12. Adrenal gland. Wikipedia, the free encyclopedia

13. WHO Global report on diabetes: A summary. IJNCD. Gojka Roglic. Department for Management of Noncommunicable Diseases, Disability, Violence and Injury Prevention, World Health Organization.

14. Obesity and overweight. 18 October 2017. World Health organization.

15. Obesity Prevention Source. Economic Costs. Harvard T.H. Chan. School of Public Health.

16. Underweight. Wikipedia, the free encyclopedia.

17. "Body Shape 'Is Down to Genes'”. Indian Express.

18. 1305. "Skinny Gene' Exists". Science Daily (2007).

19. Gjesdal., et al. "Impact of lean mass and fat mass on bone mineral density: the Hordaland Health Study". Maturitas 59 (2008): 191-200.

20. Bone Health and Osteoporosis: A Report of the Surgeon General. Office of the Surgeon General (US). Rockville (MD). NCBI.

\section{Assets from publication with us}

- Prompt Acknowledgement after receiving the article

- Thorough Double blinded peer review

- Rapid Publication

- Issue of Publication Certificate

- High visibility of your Published work

Website: $\underline{w w w . a c t a s c i e n t i f i c . c o m / ~}$

Submit Article: www.actascientific.com/submission.php Email us: editor@actascientific.com

Contact us: +919182824667 